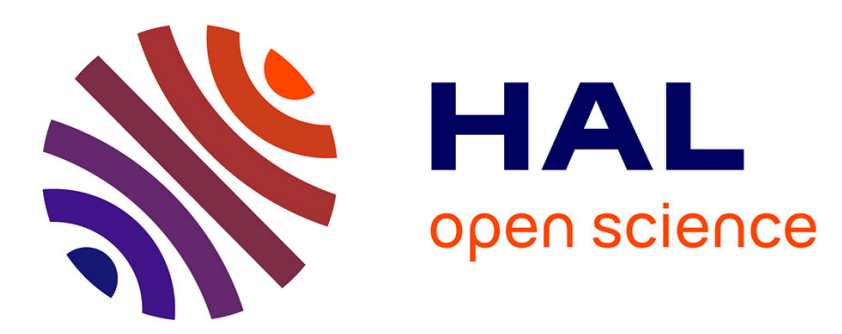

\title{
Sensitivity of deep lake temperature to past and future climatic changes: A modeling study for Lac d'Annecy, France, and Ammersee, Germany
}

\author{
P.-A. Danis, U. von Grafenstein, V. Masson-Delmotte
}

\section{To cite this version:}

P.-A. Danis, U. von Grafenstein, V. Masson-Delmotte. Sensitivity of deep lake temperature to past and future climatic changes: A modeling study for Lac d'Annecy, France, and Ammersee, Germany. Journal of Geophysical Research, 2003, 108 (D19), 10.1029/2003JD003595 . hal-02505057

\section{HAL Id: hal-02505057 \\ https://hal.science/hal-02505057}

Submitted on 11 Jan 2021

HAL is a multi-disciplinary open access archive for the deposit and dissemination of scientific research documents, whether they are published or not. The documents may come from teaching and research institutions in France or abroad, or from public or private research centers.
L'archive ouverte pluridisciplinaire HAL, est destinée au dépôt et à la diffusion de documents scientifiques de niveau recherche, publiés ou non, émanant des établissements d'enseignement et de recherche français ou étrangers, des laboratoires publics ou privés. 


\title{
Sensitivity of deep lake temperature to past and future climatic changes: A modeling study for Lac d'Annecy, France, and Ammersee, Germany
}

\author{
P.-A. Danis, ${ }^{1,2}$ U. von Grafenstein, and V. Masson-Delmotte \\ Laboratoire des Sciences du Climat et de l'Environnement, Gif-sur-Yvette, France
}

Received 13 March 2003; revised 19 June 2003; accepted 1 July 2003; published 10 October 2003.

[1] Oxygen isotope ratios $\left(\delta^{18} O\right)$ of deep-lake ostracod valves can provide excellent estimates of the oxygen isotopic composition of past atmospheric precipitation $\left(\delta^{18} O_{P}\right)$. One of the major steps of such a $\delta^{18} O_{P}$ reconstruction is the calculation of the $\delta^{18} O$ of the lake water $\left(\delta^{18} O_{L}\right)$ from the valve $\delta^{18} O$, which includes an appropriate estimate of the past water temperature during valve formation. In order to simulate changes in lake vertical temperature profile and specifically the bottom water temperature during ostracod valve formation, we have redeveloped a one-dimensional eddy diffusion thermal lake model including a lake ice model and refined it by including a seasonal light extinction model. This model was tested for two different sites, Lac d'Annecy and Ammersee. Sensitivity studies show that the ostracod calcification temperature is approaching constant $3.7^{\circ} \mathrm{C}$ for colder, but may significantly vary for warmer than present conditions. In Lac d'Annecy, such temperature effects can lead to a significant underestimation of positive $\delta^{18} O_{P}$ excursions. In Ammersee the underestimation is smaller because the hypolimnic temperatures are less sensitive to surface temperature changes. Our model can be used to better constrain such temperature effects and such further increase the quality of the $\delta^{18} O_{L}$ and $\delta^{18} O_{P}$ reconstruction. INDEX TERMS: 1845 Hydrology: Limnology; 1878 Hydrology: Water/energy interactions; 3344 Meteorology and Atmospheric Dynamics: Paleoclimatology; 4870 Oceanography: Biological and Chemical: Stable isotopes; KEYWORDS: lake thermal model, paleoclimate, benthic ostracode

Citation: Danis, P.-A., U. von Grafenstein, and V. Masson-Delmotte, Sensitivity of deep lake temperature to past and future climatic changes: A modeling study for Lac d'Annecy, France, and Ammersee, Germany, J. Geophys. Res., 108(D19), 4609, doi:10.1029/2003JD003595, 2003.

\section{Introduction}

[2] Quantitative paleoclimate reconstruction is an important task within the international effort aiming to understand the global climate system. It provides valuable information on long-term, centennial climate variability for periods not covered by instrumental observation. Climate change can be derived from floral and faunal changes as documented in various natural archives. The oxygen-isotopic composition of past precipitation $\left(\delta^{18} O_{P}\right)$ probably offers a more direct, physical link to paleoclimate, especially in mid to high latitudes, where it is positively correlated to surface air temperature [Dansgaard, 1964; Rozanski et al., 1993]. Ice cores from polar regions, for example from the center of the Greenland ice sheet, represent almost ideal archives for $\delta^{18} O_{P}$ [Jouzel et al., 1997] and have provided quantitative insights on north Atlantic climate dynamics [Johnsen et al., 1992]. In Europe, alternate isotopic archives are needed

\footnotetext{
${ }^{1}$ Also at Laboratoire de Géodynamique des Chaînes Alpines, Chambéry, France.

${ }^{2}$ Also at Agence Nationale Pour la Gestion des Déchets Radioactifs, Châtenay-Malabry, France.

Copyright 2003 by the American Geophysical Union. 0148-0227/03/2003JD003595
}

because climatic conditions prohibit the preservation of old ice. Recently, $\delta^{18} O_{P}$ records have been obtained using the isotopic composition of calcite formed by deep-lake benthic ostracods in Ammersee [von Grafenstein et al., 1996, 1999a]. The reconstruction of $\delta^{18} O_{P}$ includes two major steps: (1) the calculation of $\delta^{18} O$ of the lake water $\left(\delta^{18} O_{L}\right)$ from the $\delta^{18} O$ of the ostracod calcite by considering physiological effects and the temperature-dependent isotopic fractionation between calcite and water [Friedman and $\left.O^{\prime} N e i l, 1977\right]$; (2) the estimation of $\delta^{18} O_{P}$ from $\delta^{18} O_{L}$, accounting for possible catchment effects [Gat and Lister, 1995] and the evaporative enrichment of the lake water [Gonfiantini, 1986]. The quality of the $\delta^{18} O_{P}$ record therefore depends on how precisely those major steps of the signal transfer can be described.

[3] The physiological effects of valve $\delta^{18} O$ of major taxonomical groups of the European fresh water ostracods are well constrained [von Grafenstein et al., 1999b]. The quantitative reconstruction of $\delta^{18} O_{L}$ therefore only depends on the quantification of the water temperature during the formation of the ostracods valves. For the special case of the deep-lake ostracod-based isotope record from Ammersee, water temperature during calcite precipitation most probably was close to $4^{\circ} \mathrm{C}$, and catchment effects and lake effects in the past can be considered similar to those observed in 


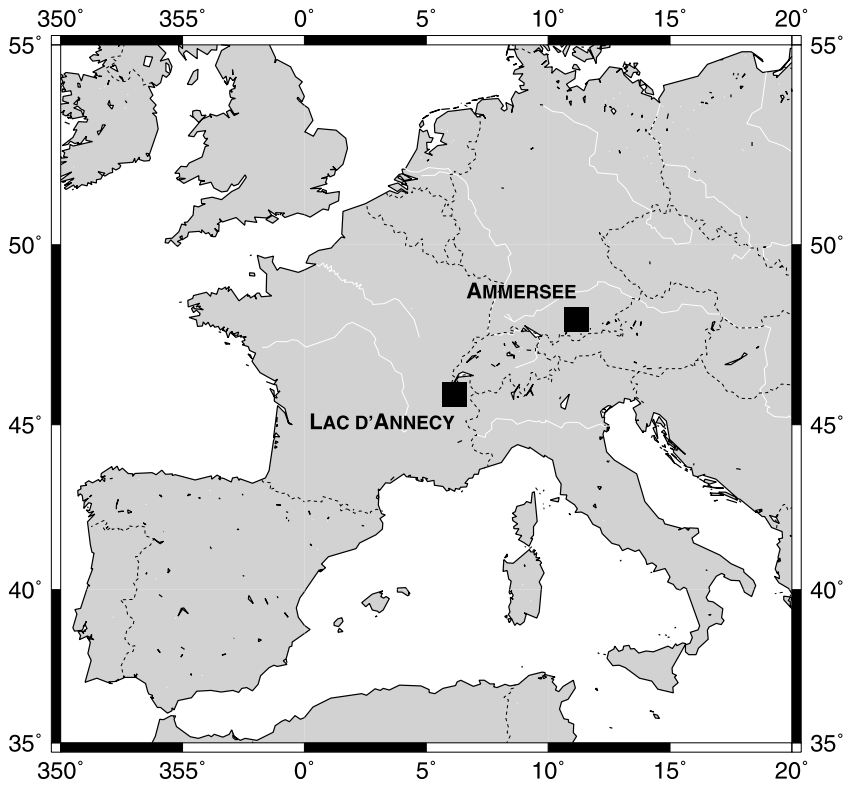

Figure 1. Location map of Lac d'Annecy $\left(6^{\circ} 07^{\prime} \mathrm{E}\right.$, $\left.45^{\circ} 54^{\prime} \mathrm{N}\right)$, France, and Ammersee $\left(11^{\circ} 10^{\prime} \mathrm{E}, 48^{\circ} \mathrm{N}\right)$, Germany.

the modern system [von Grafenstein, 2002]. The maximal bias introduced by this simplification can be assessed from a basic water balance calculations assuming extreme "worst case" climatic conditions. These uncertainties $( \pm 0.4 \%$ in the case of the Ammersee record) are small compared to the $\delta^{18} O_{P}$ signal of strong events such as, for example, the late glacial rapid changes and some major Holocene perturbations and trends. However, for large intervals during the Holocene, variations of $\delta^{18} O_{P}$ are small, leading to an overall unfavorable signal-to-noise ratio. In addition such an error estimation does not consider the dynamics of the coupled basin-lake system because it is based on steady state considerations, which is not appropriate when the amplitudes and frequencies of Holocene climate variability are analyzed. The "worst case" approach does not fully exploit the environmental information usually available from a whole range of proxies studied from the sediment cores. Moreover, the error estimation is site-specific and not easily transposable to lakes differing from Ammersee with respect to the geomorphologic, climatic, and hydrologic setting.

[4] In order to better address the bias for a given period, for strong transient changes, and for high-frequency variability, we are presently developing a fully coupled model of the basin-lake system including isotope diagnostics and the principal water and energy budgets. In its final state, the model will be used for extensive sensitivity studies, but also for the "forward" modeling of $\delta{ }^{18} O$ of the ostracod calcite from AGCM output-fields to facilitate model-data comparison, and, after inversion of the model, for an improved $\delta^{18} O_{P}$ reconstruction from different isotopic archives. That is to say the model will be adapted to simulate the $\delta^{18} O_{P}$ from the $\delta^{18} O$ of the ostracod calcite and of others archives of the $\delta^{18} O$ of the lake water.

[5] Here we focus on the lake thermal structure which is one fundamental part of such an integrated model. The mainly temperature-controlled density profile influences the import of the $\delta^{18} O_{P}$ signal into the lake, is important for its distribution in the lake itself, has a strong impact on evaporation and the related isotopic fractionation at the lake's surface, and last but not least, is the main control of temperature-dependent fractionation during the signal preservation.

[6] We have developed a numerical lake model able to simulate observed temperature profiles, and tested this model for two different sites: the monomictic Lac d'Annecy $\left(6^{\circ} 07^{\prime} \mathrm{E}, 45^{\circ} 54^{\prime} \mathrm{N}\right)$ and the dimictic Ammersee $\left(11^{\circ} 10^{\prime} \mathrm{E}\right.$, $48^{\circ} \mathrm{N}$ ) (Figure 1). Realistic control simulations have been obtained by scaling the micrometeorological observations, which are not available for the middle of the lakes, and by taking into account seasonal changes in the light extinction coefficient. Special attention was given to the validation of the simulated vertical water temperature profiles by forcing, alternatively, with daily meteorological observations, with monthly averaged data, and with multiyear monthly means.

[7] We have then used this model to quantify possible changes of the lakes' mixing behavior and of the bottom lake temperature in response to various climatic scenarios with warmer or colder than modern conditions. As a result, we can constrain the part of the benthic ostracod calcite isotopic composition related to changes in calcification temperature and, by correcting for it, further increase the quality of the $\delta^{18} O_{L}$ and $\delta^{18} O_{P}$ reconstruction.

\section{Lake Model Development and Tuning Methodology}

\subsection{Lake Model}

[8] The bottom water temperature of a lake is mainly a result of climatically controlled seasonal changes of the lake's vertical temperature-dependent density distribution. During spring and summer, the gradual superficial warming induces the formation of a warm and light surface layer (epilimnion) isolated from a denser and colder bottom layer (hypolimnion) by a transition zone with a more or less steep temperature gradient (thermocline). Wind stress and relative temperature decreases facilitate the mixing of the epilimnion, and thus control the depth and the sharpness of the transition to the hypolimnion. Starting in the fall and continuing into the winter, surface cooling leads to increasingly deeper convection and increasing density of the epilimnion, cumulating in a complete overturn, when the hypolimnetic temperature and density is reached. In dimictic freshwater lakes, the full mixing period occurs when the surface and deep lake temperature is close to $4{ }^{\circ} \mathrm{C}$, the maximum density of freshwater, separated by a phase of stabilization with a colder epilimnion. In warmer and/or monomictic lakes, the full-mixing temperature can be higher than $4^{\circ} \mathrm{C}$ and climatic changes will induce fluctuations in mixing and hypolimnetic temperature.

[9] Here it is our goal to develop a thermal lake model which can be easily adapted to different lakes, and which allows numerous runs for sensitivity studies. However, it should still be able to capture the main characteristics of the vertical structure of the lakes, i.e., surface and bottom water temperatures, thermocline depth, and onset and duration of the winter mixing. We therefore have opted for a one- 


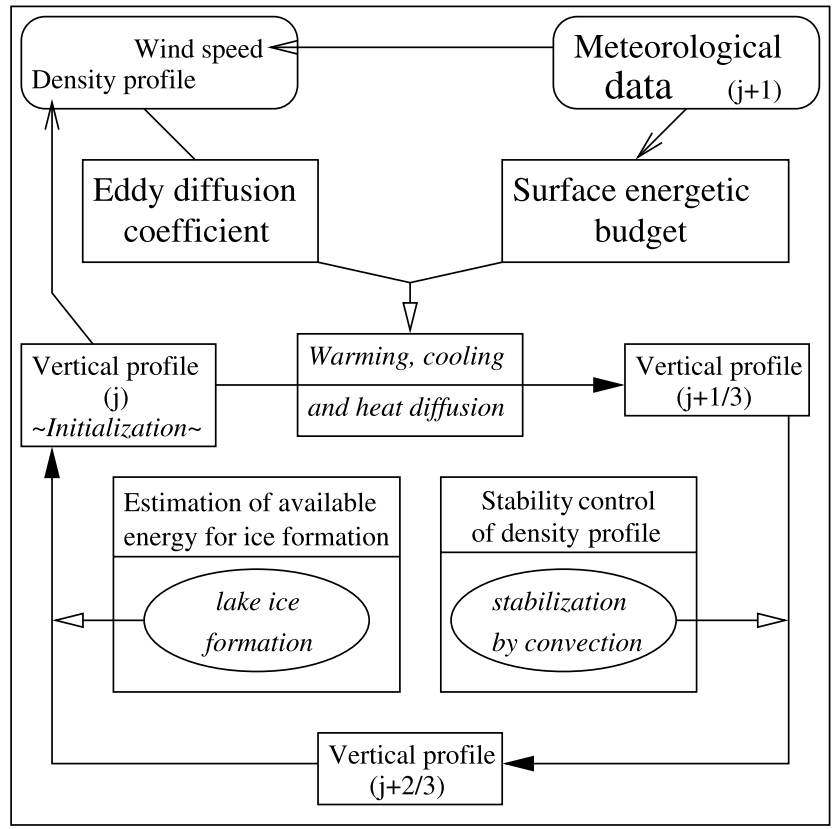

Figure 2. Algorithm of the one-dimensional eddy diffusion model. The simulation is initialized by an observed vertical lake water temperature profile (vertical profile). The estimation of the vertical profile of the following day needs (1) the calculation of the eddy diffusion coefficient along the water column depending on the vertical water density profile of the previous day $(\mathrm{j})$ and on the wind speed above the lake surface of the following day $(j+1) ;(2)$ the calculation of the surface energetic budget mainly depending on the meteorological data of the following day $(\mathrm{J}+1)$; (3) after the warming and/or the cooling of each lake water layer of $1 \mathrm{~m}$ thick, the model controls the density stability of the new vertical profile $(j+1 / 3)$ and does the required stabilization; and (4) if the surface lake water temperature of the $j+2 / 3$ profile decreases below the freezing point of freshwater, the model induces lake ice formation and fixes the surface lake water temperature of the new profile $(j+1)$ at the temperature of this freezing point.

dimensional description of the vertical transfer of heat simulated by eddy diffusion and convective mixing. Our model has been redeveloped from mathematical equations based on Hostetler and Bartlein [1990] and following the pioneering work of Orlob and Selna [1970] and HendersonSellers $[1985,1986]$. We ignore the small thermal effects of incoming river waters and of the lake borders [Hostetler and Bartlein, 1990; Carmack and Farmer, 1982]. Previous studies have already demonstrated that such simple models can be used to simulate the vertical thermal structure, surface water temperature, evaporation rates, and lake level fluctuations of a variety of lakes and climatic situations [Hostetler and Bartlein, 1990; Vassiljev et al., 1994; Liston and Hall, 1995; Peeters et al., 2002; Benson and Paillet, 2002]. They have also been used in paleoclimate applications [Hostetler and Benson, 1990; Hostetler, 1991; Vassiljev et al., 1995; Vassiljev, 1998; Vassiljev and Harrison, 1998], in $\delta^{18} O$ isotopic studies [Hostetler and Benson, 1994] and in climate change assessments [Hostetler and Giorgi, 1995].
[10] In our case, Lac d'Annecy and Ammersee have been extensively monitored during the past decade. The resulting database of intra-annual to interannual vertical temperature profiles will be exploited to calibrate the model both for high (intramonthly) and low (seasonal) frequencies.

[11] Our one-dimensional model (Figure 2) is composed of three major submodels: (1) a surface-energy balance submodel [Henderson-Sellers, 1984, 1986] to determine the surface temperature and energy available to heat the water column; this submodel is forced by the basic meteorological parameters (surface air temperature, humidity, wind speed, cloud cover, solar radiation). (2) an eddy diffusion model [Henderson-Sellers, 1985] describing the evolution of water temperature and stratification; this submodel is forced by the bathymetry of the lake and by a light extinction coefficient $(\eta)$. The heat diffusion equation is numerically solved using the Cranck-Nicholson technique requesting a restriction on the time step $\Delta t$ [Hostetler and Bartlein, 1990] calculated each day depending on the maximum eddy diffusion coefficient with a depth step fixed to $1 \mathrm{~m}$. The temperature-density relationship [Heggen, 1983; Hostetler and Bartlein, 1990] ignores the pressure dependency of freshwater density; the associate bottom temperature bias is smaller than $0.2^{\circ} \mathrm{C}$ [Farmer and Carmack, 1982] for the relatively shallow two lakes considered here. (3) an ice and snow accumulation submodel [Patterson and Hamblin, 1988] to account for the specific energy and mass fluxes during ice and snow cover which will be significant for extreme years in the validation period and especially for the simulation in cold climates; we do not consider a fractional ice cover and assume that the full area of the lakes freezes simultaneously.

[12] Simulations are initialized with observed homogenized thermal profiles. The full model is forced by the bathymetry of the lake, the basic meteorological parameters, and the light extinction coefficient in the water $(\eta)$. The scaling needed for the meteorological parameters, which are not available in the middle of each lake, and the implementation of a light extinction coefficient model are discussed below.

\subsection{Seasonal Light Extinction Model}

[13] The light extinction coefficient controls the decreasing penetration of short-wave radiation below the lake surface and therefore the absorption of heat in deeper parts of the lake. Visual measurements (Secchi-disk disappearing depth) [Pourriot and Meybeck, 1995] show large spatial and temporal variations of $\eta$ due to the amount of suspended matter and algal productivity. Although such seasonal variations are explicitly mentioned, mean values are used in all modeling studies known to us [see, e.g., Vassiljev et al., 1994; Peeters et al., 2002]. The amount of suspended matter depends on the river input and its location in the water column can vary with the density/temperature profile of the lake. Owing to its relationship with abrupt precipitation events, this factor should play a dominant role for the high-frequency, intramonthly variations of $\eta[$ van Duin et al., 2001]. Algal productivity is a function of energy and nutrient availability in the epilimnion; it controls mainly the low-frequency, seasonal variations of $\eta[$ van Duin et al., 2001]. 
[14] As our model is mainly designed to correctly simulate seasonal fluctuations of the bottom water temperature, we only consider seasonal $\eta$ variations. Moreover, spring interfloods and overfloods induce temporarily high $\eta$ values, which are balanced by lower $\eta$ levels during midsummer time. Sensitivity studies have been performed with different seasonal $\eta$ models, and compared with the observed Lac d'Annecy seasonal hypolimnetic temperature fluctuations. Simulations with a weak and constant $\eta$ are compatible with observed mean hypolimnetic temperature but fail to represent the seasonality of the bottom water temperature, particularly for Lac d'Annecy. The best simulations are obtained when a seasonal model is implemented with a sinusoidal function between spring and fall, and constant values during winter (equations (1) and (2)). This enables us to predict "as observed" heat accumulation in the deeper part of the water column in winter, which may play an important role in the winter mixing of the lake during relatively mild winters. In this case not only the surface temperature cooling, but also the subdued warming of the hypolimnion, helps to start convection.

If $90 \leq J<333$

$$
\eta^{\prime}=\bar{\eta}+\frac{\bar{\eta}}{\Delta \eta} \sin \left(2 \pi \frac{J-151}{244}\right)
$$

If $J<90$ or $J \geq 333$

$$
\eta^{\prime}=\bar{\eta}-\frac{\bar{\eta}}{\Delta \eta},
$$

where $\eta^{\prime}$ is the daily light extinction coefficient, $\bar{\eta}$ is the yearly light extinction coefficient, $\Delta \eta$ is the correction of the seasonal amplitude of $\eta$, and $J$ is the Julian day.

\subsection{Scaling of Meteorological Forcing}

[15] Meteorological observations are available from sites near the two lakes chosen for our study, but not from the lake surfaces. The observations thus may be biased and should be corrected for micrometeorological effects. To account for micrometeorological effects several factors should be considered. First, vertical gradients to account for different elevations between the lake surface and the meteorological station. The two well-known vertical gradients are those of the air temperature $T$ $\left(-0.6^{\circ} \mathrm{C} / 100 \mathrm{~m}\right)$ and of the atmospheric pressure $P$ $(-1000 \mathrm{~Pa} / 100 \mathrm{~m})$. Both gradients are included in the factors $\Delta \bar{T}$ (equation (3)) and $\Delta P$ (equation (4)). Second, lateral effects to account for the influence of the lake itself and of the surrounding topography, respectively, such as mentioned by Liston and Hall [1995]. The effect of the water body on the air mass temperature is taken into account by a sinusoidal function and a correction factor of the seasonal amplitude ( $\triangle a m p l \bar{T}$, equation (4)).

[16] In addition to the scaling parameters of the air temperature and the atmospheric pressure, the vertical and lateral variations of wind speed $w$, cloud cover $C C$, and relative humidity $R H$ are taking into account by $\Delta w$ (equation (5)), $\triangle C C$ (equation (6)), and $\Delta R H$ (equation (7)), respectively.
[17] The corrected values are written as:

$$
\begin{gathered}
T^{\prime}=T+\Delta \bar{T}+\frac{\Delta a m p l}{2} \operatorname{T} \sin \left(2 \pi \frac{J-103}{366}\right) \\
P^{\prime}=P+\Delta P \\
w^{\prime}=w \times \Delta w \\
C C^{\prime}=C C \times \Delta C C \\
R H^{\prime}=R H \times \Delta R H,
\end{gathered}
$$

where $J$ is the Julian day.

[18] Consequently, the external and scaling parameters used here are meteorological parameters, mainly because the meteorological station is not situated on the middle of the lake and the lakes themselves cause local micrometeorological variations and parameters of the light extinction coefficient model ( $\eta$ and $\Delta \eta$ ) because water observations are discrete measurements in time and in space. The scaling was constrained by local meteorological studies using a second nearby station and by running the lake model under climatological forcing, i.e., with the multiyear average of the monthly observations (see section 3.3).

\section{Results and Discussion}

[19] The model was applied to two lakes located in midEurope (Figure 1), Lac d'Annecy (France) and Ammersee (Germany) for which a wealth of meteorological and lake instrumental observations are available for the past decade. Both lakes are suitable for the reconstruction of past $\delta^{18} O_{P}$ because their hydrological balance is dominated by surface water input and their depth prevents large fluctuations of the hypolimnetic water temperatures. However, due to their slightly different geographical positions and their different climatic settings and topographies, they can also serve as a test for the model's reliability and adaptability.

[20] After briefly presenting the two lakes and the available observations, we discuss the model calibration and compare the simulations obtained with climatological, monthly and daily forcing. We then test the ability of the model to simulate estimated mean hypolimnetic temperature and the interannual variations of the calcification temperature of Candonidae, the taxonomic group of ostracods preferentially used for the isotopic studies. Last, steady state sensitivity studies of past and future climatic states enable us to evaluate the response of the ostracod calcification temperature to various forcings.

\subsection{Characteristics of Lac d'Annecy and Available Instrumental Observations}

[21] Lac d'Annecy $\left(6^{\circ} 07^{\prime} \mathrm{E}, 45^{\circ} 54^{\prime} \mathrm{N}\right.$; surface area $27.5 \mathrm{~km}^{2}$; length $13 \mathrm{~km}$; width $2.2 \mathrm{~km}$; maximum depth $65 \mathrm{~m})$ is oriented north-south and divided in two main basins: the northern Grand Lac with a maximal depth of $65 \mathrm{~m}$ and the southern Petit Lac with a maximum depth of 


\section{Lac d'Annecy}
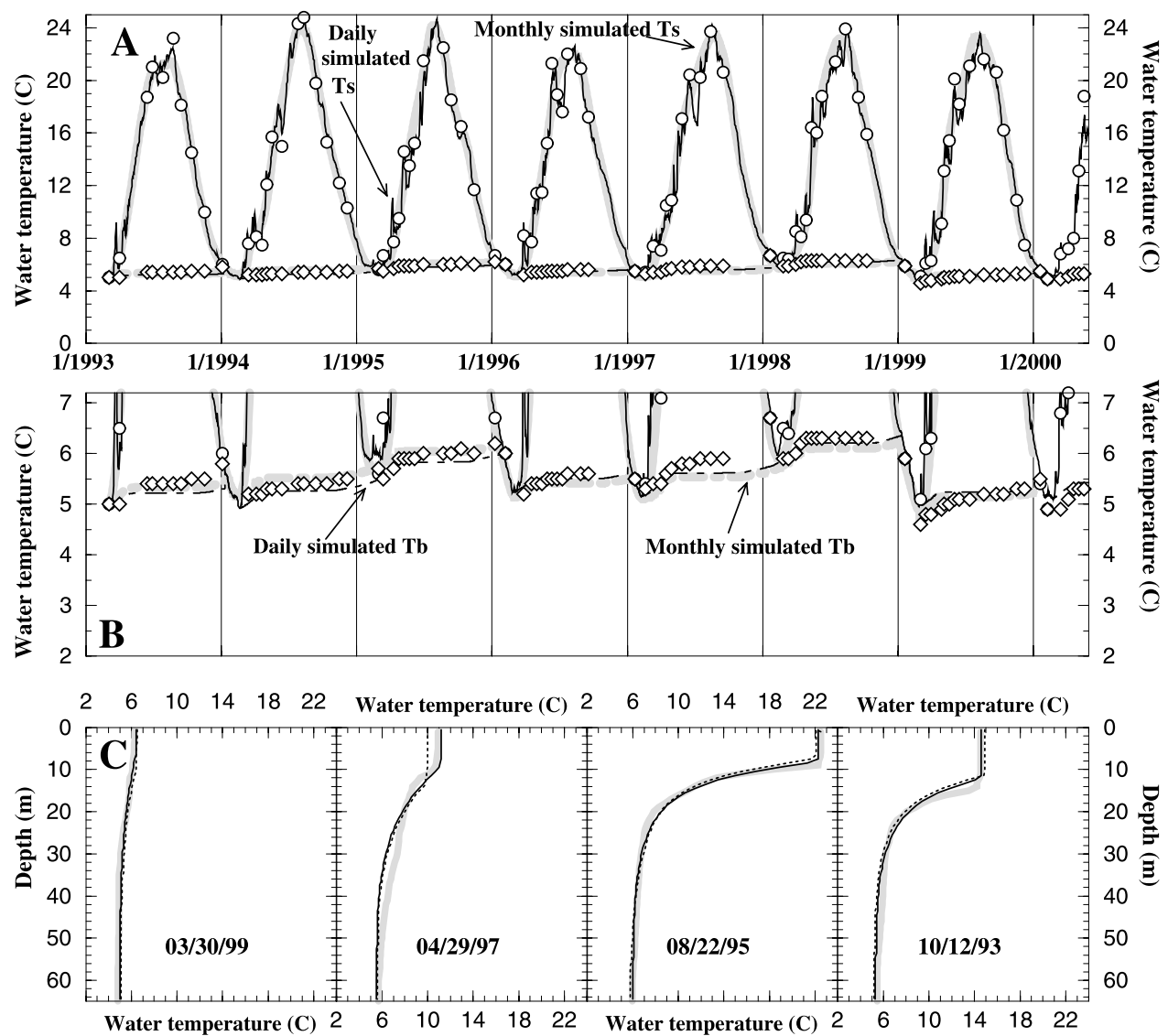

Figure 3. Best monthly and daily meteorological simulations. (a) Monthly (large gray lines) and daily (fine black lines) simulations of surface and bottom water temperature. (b) Zoom on the bottom water temperature. (c) Typical monthly (solid lines) and daily (dotted lines) simulated vertical profiles. Circles (surface water temperature in Figures 3a and 3b), diamonds (bottom water temperature in Figures 3a and $3 \mathrm{~b}$ ) and large gray lines (vertical temperature profiles in Figure 3c) are observational data from Grand Lac d'Annecy.

$55 \mathrm{~m}$ which are separated by a sill at $45 \mathrm{~m}$ water depth. We use a surface-depth distribution in 1-m depth steps derived from a digital elevation model obtained from an echo sounding survey done in 1993. The calculated water residence time is approximately 3.8 years [BenedettiCrouzet, 1972].

[22] Vertical lake temperature profiles have been measured at $1 \mathrm{~m}$ intervals once per month from 1990 to 1999 in the middle of the two main basins (data provided by the Syndicat Intercommunal du Lac d'Annecy, SILA). The multiparameter probe measures temperature corrected for the adiabatic effect within $\pm 0.01^{\circ} \mathrm{C}$. The observed difference in near-surface temperatures between Grand Lac and Petit Lac probably is in part due to the time lag between the measurements and exhibits the local differences from wind stress and internal waves. Lateral temperature gradients are typically $\sim 2^{\circ} \mathrm{C}$ and the depth of the thermocline can vary up to $3 \mathrm{~m}$. Figure $3 \mathrm{a}$ shows successive instantaneous surface and bottom water temperatures from the Grand Lac which capture well the various stages of the seasonal cycle: stratification period, stratification breakdown, isothermal overturning. After the winter homogenized period, stratification takes place and bottom temperature increases slowly until midsummer. For model calibration, we have considered only temperature profiles from the largest basin (Grand Lac).

[23] Bimonthly proxy observations of light extinction (Secchi disc disappearance depth) are available for two specific years, 1990 and 1998 (SILA). The mean light extinction coefficient computed from these observations is $0.24 \mathrm{~m}^{-1}$, with extremes of 0.15 to $0.43 \mathrm{~m}^{-1}$, respectively.

[24] The closest meteorological station (Meythet, MétéoFrance) is located $3 \mathrm{~km}$ northward of the lake, upstream from the main wind direction, and $11 \mathrm{~m}$ above the lake level; daily data are available from 1993 to 1999. At Lac d'Annecy, Benedetti-Crouzet [1972] used a second meteorological station and pointed significantly different seasonal air temperature amplitude on opposite sides of the lake $\left(-4^{\circ} \mathrm{C}\right.$ in the main wind direction). This difference is most probably due to the lake's thermal inertia and gives the range of credible variations of $\triangle a m p l \bar{T}$ (Table 1).

\subsection{Characteristics of Ammersee and Available Instrumental Observations}

[25] Ammersee, a single basin lake, is significantly larger and deeper than Lac d'Annecy $\left(11^{\circ} 10^{\prime} \mathrm{E}, 48^{\circ} \mathrm{N}\right.$; surface area, 
Table 1. Values of the Scaling Parameters

\begin{tabular}{lcccc}
\hline & \multicolumn{2}{c}{ Lac d'Annecy } & \multicolumn{2}{c}{ Ammersee } \\
\cline { 2 - 4 } & Range $^{\mathrm{a}}$ & Calibration $^{\mathrm{b}}$ & Range $^{\mathrm{a}}$ & Calibration $^{\mathrm{b}}$ \\
\hline$\Delta \bar{T},{ }^{\circ} \mathrm{C}$ & $-1.5 \sim 0$ & -0.9 & $0.5 \sim 2.5$ & 1.4 \\
$\Delta a m p l \bar{T},{ }^{\circ} \mathrm{C}^{\mathrm{c}}$ & $-4 \sim 0$ & $-1.6 /-2.6 /-3.4$ & $-5 \sim 0.8$ & $-2.4 /-2.4 /-3.4$ \\
$\eta, \mathrm{m}^{-1}$ & $0.15 \sim 0.43$ & 0.21 & $0.2 \sim 0.94$ & 0.24 \\
$\Delta \eta$ & $1.5 \sim 4.5$ & $581 / 612 / 577$ & & \\
$E, \mathrm{~mm} /$ year $^{\mathrm{c}}$ & $540 \sim 665$ & & & \\
\hline${ }^{\mathrm{a}}$ Ranges of variation for the scaling parameters. & & & \\
${ }^{\mathrm{b}}$ Results of the model calibration. & & &
\end{tabular}

$46.5 \mathrm{~km}^{2}$; length, $15 \mathrm{~km}$; mean width $3.5 \mathrm{~km}$; maximum depth $81 \mathrm{~m}$ ). Its annual residence time is about 2.7 years. The lake topography is estimated from a bathymetric map at 8 depths between the surface and the maximum depth $81 \mathrm{~m}$ (Alpen-Verlag, München) and interpolated to a $1 \mathrm{~m}$ depth interval, similar to that of Lac d'Annecy.

[26] Monthly temperature profiles are available from 1993 to 2000. Temperature measurements were performed every 2 or $3 \mathrm{~m}$ between the surface to $16 \mathrm{~m}$ depth and each $10 \mathrm{~m}$ from $20 \mathrm{~m}$ depth to $80 \mathrm{~m}$ depth (Wasserwirtschaftsamt Weilheim, Oberbayern, WW). These observations have been done by sampling of water from a specific depth and thus can be biased by thermal exchange between sampled water and the surrounding water column, specially for bottom samples. Comparison with 28 simultaneous probe measurements (WW, not shown here) suggests large uncertainties on the observed hypolimnetic temperatures (typically $0.5^{\circ} \mathrm{C}$ ) used for model calibration. Time series plots of instantaneous surface and bottom temperatures of Ammersee (Figure 4a) show the separate stages of the seasonal cycle: stratification period, stratification breakdown and two isothermal overturnings separated by an inverse stratification. The mean light extinction coefficient computed from observations as was done for Lac d'Annecy (1993-1994) is equal to $0.32 \mathrm{~m}^{-1}$, with extreme values ranging from $0.2 \mathrm{~m}^{-1}$ to $0.94 \mathrm{~m}^{-1}$.

[27] The closest meteorological station is located $24 \mathrm{~km}$ southward of the lake and $443 \mathrm{~m}$ above the lake level
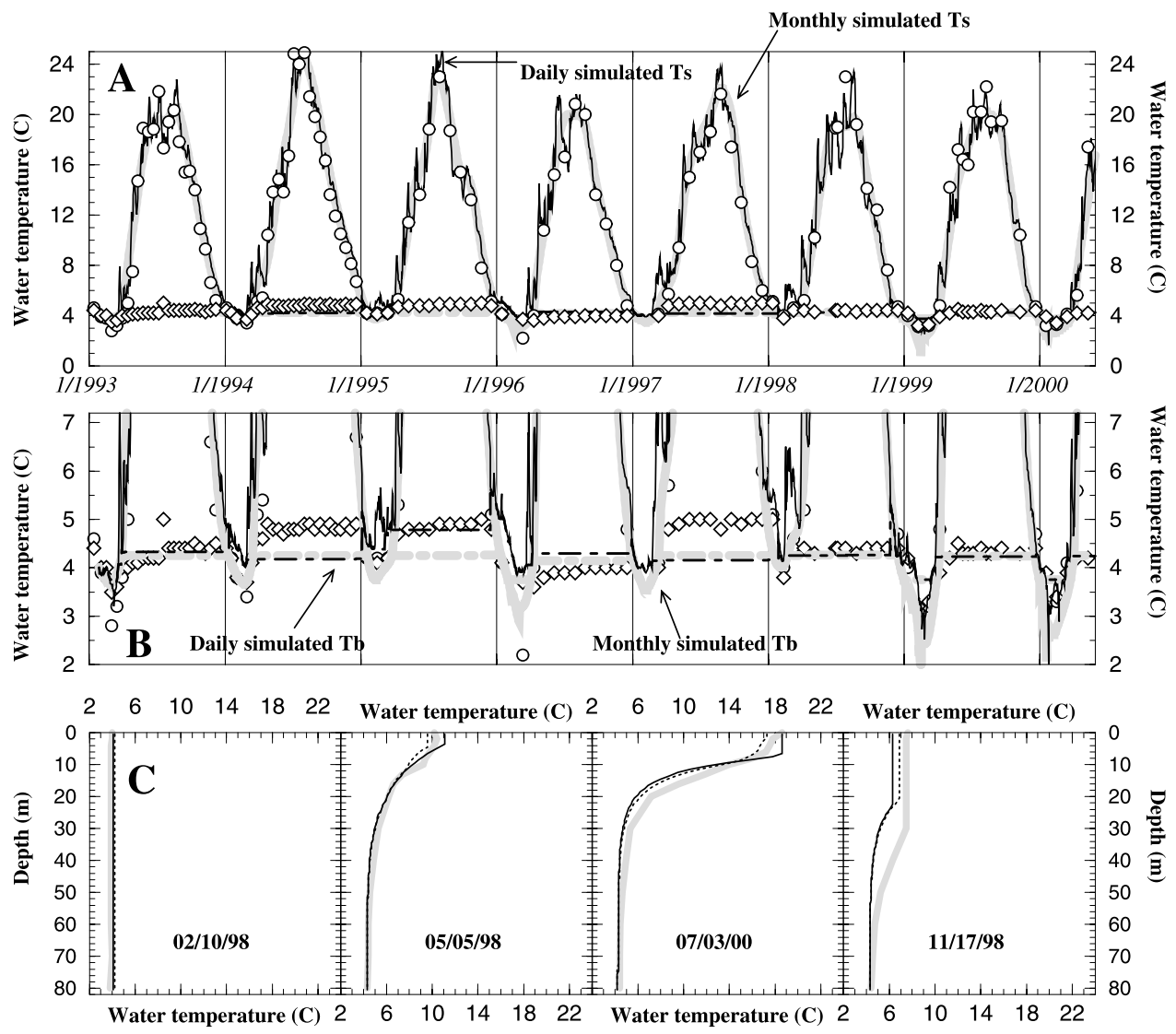

Figure 4. Best monthly and daily meteorological simulations. (a) Monthly (large gray lines) and daily (fine black lines) simulations of surface and bottom water temperature. (b) Zoom on the bottom water temperature. (c) Typical monthly (solid lines) and daily (dotted lines) simulated vertical profiles. Circles (surface water temperature in Figures $4 \mathrm{a}$ and $4 \mathrm{~b}$ ), diamonds (bottom water temperature in Figures $4 \mathrm{a}$ and $4 \mathrm{~b}$ ) and large gray lines (vertical temperature profiles in Figure 4c) are observational data from Ammersee. 
Table 2. Local Variations of Meteorological Parameters Observed Near Ammersee

\begin{tabular}{lcccc}
\hline & $\begin{array}{c}\text { Observed Vertical Gradient } \\
\text { (Hohen-Attenkam)/100 m }\end{array}$ & $\mathrm{R}^{2}$ & $\begin{array}{c}\text { Number of } \\
\text { Monthly Values }\end{array}$ & $\begin{array}{c}\text { Estimated Correction } \\
\text { (Hohen-Ammersee) }\end{array}$ \\
\hline $\bar{T},{ }^{\circ} \mathrm{C}$ & -0.33 & $>0.99$ & 348 & +1.46 \\
${\text { amplT },{ }^{\circ} \mathrm{C}^{\mathrm{a}}}$ & -0.24 & 0.89 & 17 & -1.1 \\
$w, \mathrm{~m} \mathrm{~s}^{-1}$ & +0.07 & 0.92 & 348 & $-10 \%$ \\
$R H, \%$ & -0.5 & 0.63 & 353 & $+3 \%$ \\
$C^{\mathrm{b}}{ }^{\mathrm{b}}$ & $<0.01$ & 0.97 & 14 & $\simeq 0$ \\
\hline
\end{tabular}

${ }^{a}$ Estimation with yearly values between 1984 and 2000 .

${ }^{b}$ Estimation with values between 2000 and 2001.

(Hohenpeißenberg, Deutscher Wetterdienst, DWD). Data are available continuously from 1993 to 2000 simultaneously with water temperature observations. Clearly, these meteorological data need to be scaled to be representative of the climatic situation above the lake surface. We use a second, nearby station, Attenkam (DWD, $672 \mathrm{~m}$ asl), to estimate the lateral and vertical variability of each meteorological parameter (Table 2).

\subsection{Climatological Simulations and Model Tuning}

[28] The climatological forcing was obtained from monthly averages of the daily meteorological observations between 1993 and 1999 (2000 at Ammersee). The monthly values of parameters are centered on the fifteenth of each month and linearly interpolated for reconstructing daily values used by the lake model. Consequently, the model will not be able to simulate intramonthly water temperature fluctuations.

[29] The climatological lake temperature profiles were obtained by averaging interannual observations for each month between 1993 and 1999 (2000 at Ammersee). The uncertainty of these mean profiles depends on the number of instantaneous measurements involved and their intramonthly repartition (horizontal and vertical error bars displayed on Figure 5).

[30] Forcing the model by climatological observations, we adjusted the scaling factors to fit the lake water temperature with the calculated climatological lake temperature
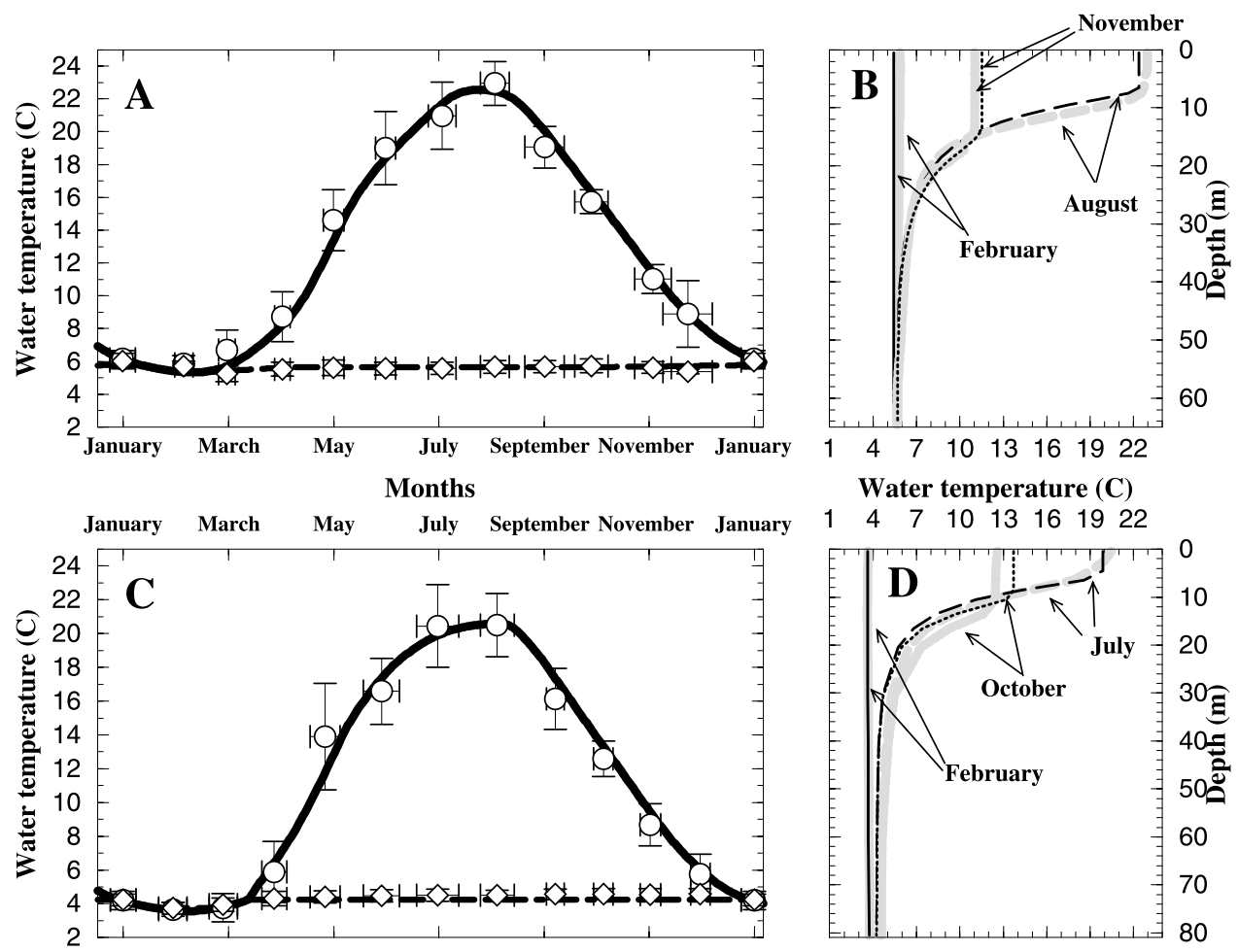

Figure 5. Best climatological simulations and monthly observations of surface water temperature (circles in Figures 5a and 5c), of bottom water temperature (diamonds in Figures 5a and 5c) and of three monthly profiles at (b) Lac d'Annecy and at (d) Ammersee. (a and c) The time uncertainties (horizontal error bars) are estimated by subtracting a standard deviation of the profile days from the number of the centered day in the month (15). The vertical error bars show one standard deviation of the observed water temperature. ( $b$ and d) The climatological observations of lake temperature profiles (large gray lines) were obtained by averaging interannual observations for each month between 1993 and 1999 (2000 at Ammersee). And the three simulated (fine lines) profiles are monthly averages of daily simulated profiles. Theses profiles illustrate the stratification of the water column during the summer time and the homogenization period during the winter time. 
Table 3. Effect of the Negligible Parameters on the Ostracod Temperature, $T_{O}$

\begin{tabular}{lccccc}
\hline & \multicolumn{2}{c}{ Lac d'Annecy } & & \multicolumn{2}{c}{ Ammersee } \\
\cline { 2 - 3 } \cline { 5 - 6 } &, $\pm \%$ & $T_{O} \pm,{ }^{\circ} \mathrm{C}$ & &, $\pm \%$ & $T_{O} \pm,{ }^{\circ} \mathrm{C}$ \\
\hline$\Delta R H$ & 5 & 0.12 & & 3 & 0.05 \\
$\Delta C C$ & 5 & 0.10 & & 5 & 0.01 \\
$\Delta P$ & 10 & 0.00 & & 10 & 0.00 \\
\hline
\end{tabular}

profiles. A purely mathematical inversion minimizing a cost function calculated for each simulation and each parameter combination is difficult for our nonlinear model which can create local minima. We have therefore developed an empirical scaling methodology to select the forcing parameters for which the scaling seems to be very sensitive $(\Delta \bar{T}$, $\Delta a m p l \bar{T}, \eta, \Delta \eta$ and $\Delta w$ ) compared to parameters for which the scaling is easily obtained $(\triangle R H, \triangle C C$ and $\Delta P)$. Consequently, for the two sites, $\Delta P$ was corrected by the observed altitudinal gradient. $\triangle R H$ and $\triangle C C$ were fixed to 1 because observed local variations are negligible.

[31] For Lac d'Annecy, we neglected lateral variations of wind speed between the meteorological station and the lake surface because the meteorological station is sufficiently close to the lake $(\Delta w=1)$. Subsequently, we simultaneously adjusted $\Delta \bar{T}, \Delta a m p l \bar{T}$ to roughly fit the simulated surface water temperature to the observations. After that, we tuned $\eta$ and $\Delta \eta$ to simulate the observed fluctuations of the temperature of the bottom water. And finally, we readjusted $\Delta \bar{T}$ and $\Delta a m p l \bar{T}$. The resulting values of the scaling parameters are summarize in Table 1.

[32] For Ammersee, we first fixed the $\eta$ based on the mean difference between both lakes' observations and conserved the $\Delta \eta$ which was tuned for Lac d'Annecy. After that, we calculated $\Delta \bar{T}$ considering the observed local altitudinal gradient (Table 2). We third adjusted the wind speed (with $\Delta w$ ) to obtain evaporation rates close to estimation based on stable isotopes [von Grafenstein, 2002]. And, finally, we adjusted $\Delta a m p l \bar{T}$ and readjusted $\Delta \bar{T}$. The resulting values of the scaling parameters are summarize in Table 1.

[33] For the meteorological adjusting factors which have not been tuned $(\triangle R H, \Delta C C$ and $\Delta P)$, we have performed sensitivity studies confirming a small impact of their observed spatial variations on the bottom water temperature (Table 3). The final climatic situations on lakes' surface after micrometeorological scaling are summarized in the Table 4 .

[34] The Figure 3 for Lac d'Annecy and the Figure 4 for Ammersee show modeled and observed surface and bottom water temperatures as well as four representative monthly vertical profiles (Figures $3 \mathrm{c}$ and $4 \mathrm{c}$ ). The light extinction parameterization and the scaling of the meteorological observations based on micrometeorological considerations result in good agreement between the simulations and the modern observations. The model not only reproduces the seasonal cycle of the surface lake temperature but also captures the much smaller seasonality of the hypolimnetic water temperature and the monthly thermocline depth which are key points with respect to the bottom water temperatures during the period of valve formation of candonidae, the group of ostracods used for the $\delta^{18} O$ record in Ammersee and Lac d'Annecy. For Lac d'Annecy, the simulated evap- oration (Table 1) is in good agreement with previous estimate [Benedetti-Crouzet, 1972] which is an indirect check of the model performance. For Ammersee, the lake evaporation was used to scale the wind speed forcing, which was necessary due to the larger vertical and horizontal distances between the meteorological stations and the lake.

\subsection{Interannual Simulations With Daily and Monthly Forcing}

[35] Our thermal lake model enables a correct climatological simulation which is necessary for climatic sensitivity studies. However, high frequency meteorological variations such as persistent weekly warm or cold conditions, and strong winds can have large impacts on instantaneous lake temperature profiles. We therefore have also tested the model response to forcing by both daily observations and monthly observations. These tests not only provide an additional control of the model performance, but also are necessary if the model is used to study the potential impact of high frequency variability under different climatic conditions.

[36] For monthly and daily meteorological forcings only, the seasonality of air temperature $(\triangle a m p l \bar{T})$ had to be adjusted to obtain a reasonable fit to the observed temperature profiles. This scaling parameter always ranges within the lateral fluctuations observed, and the resulting evaporation rates are also consistent with local estimates (Table 1).

[37] For both lakes, the surface temperatures calculated with monthly and daily forcing show no drift and no systematic bias over the 7-years long simulation period (Figures $3 \mathrm{a}$ and $4 \mathrm{a}$ ). The model also captures observed interannual lake surface temperature fluctuations which are common to the two sites, as, for example, the warmest and coldest summer surface temperature in 1994 and 1996, respectively, and the two coldest winters (1998-1999 and 1999-2000). When the daily forcing is used, the model is also able to simulate intramonthly surface temperature fluctuations in response to the high frequency meteorological variability. For instance, a rapid cooling $\left(4^{\circ} \mathrm{C}\right)$ observed in both lakes during summer 1996 is well simulated by our model and is due to an episode of extraordinary cold air temperatures at the beginning of the summer at both sites. These results confirm that Lac d'Annecy and Ammersee, which are about $450 \mathrm{~km}$ apart, undergo similar interannual climatic fluctuations, providing support for the use of similar forcing at both sites for sensitivity studies.

[38] For deep lake water temperatures, the daily forcing has little impact and gives the same results as the monthly forcing due to the thermal inertia of such deep lakes. For Lac d'Annecy, the model, with both forcings, is able to

Table 4. Recent Climatic Situations Resulting From Climatological Calibration

\begin{tabular}{lcc}
\hline & Lac d'Annecy $^{\mathrm{a}}$ & Ammersee $^{\mathrm{b}}$ \\
\hline $\bar{T},{ }^{\circ} \mathrm{C}$ & $10.0(2.3 \sim 18.4)$ & $9.1(2.5 \sim 16.6)$ \\
amplT,${ }^{\circ} \mathrm{C}$ & 16.1 & 14.1 \\
$w, \mathrm{~m} \mathrm{~s}^{-1}$ & $2.0(1.7 \sim 2.4)$ & $2.5(1.9 \sim 3.3)$ \\
$C C$ & $0.53(0.40 \sim 0.72)$ & $0.61(0.52 \sim 0.73)$ \\
$R H, \%$ & $76.0(69.0 \sim 84.3)$ & $76.6(72.3 \sim 83.0)$ \\
$P, \mathrm{hPa}$ & $963(959 \sim 965)$ & $949(945 \sim 952)$. \\
\hline
\end{tabular}

${ }^{\mathrm{a}}$ From data of Meythet (Météo France).

${ }^{b}$ From data of Hohenpeißenberg (DWD). 
capture some of the observed interannual variability for instance, the warmest temperatures in 1998 and coldest temperatures in 1999. However, the model fails to simulate two observed homogenizations in 1995 and 1998, possibly due to a scaling problem for two extreme meteorological situations. In 1995, the model is too sensitive to low winter mean wind speeds, the lowest of the 1993-2000 time period, which reduces the surface cooling and inhibits full mixing. In 1998, the deep lake temperatures are particularly cold from summer to winter, within the meteorological context of a cool winter. As a result, the model maintains stratification all year round but with a very small temperature difference between the surface and bottom of the lake. Two factors may explain this failure: first, the model probably underestimates the eddy diffusion during early spring stratification (spring 1997) with particularly high wind speeds smoothed by the multiyear scaling method which induces deep temperatures to be too cold from spring 1997 to winter 1997-1998. Second, it is possible that a particularly low yearly light extinction coefficient has favored the observed warming of deep lake temperature and enabled the homogenization in the real lake.

[39] For Ammersee, the model is less realistic than for Lac d'Annecy in terms of interannual changes of deep lake temperature. Nonlinear lake density fluctuations occur easily here because the lake bottom water temperature is near the temperature of maximum density for water $\left(4^{\circ} \mathrm{C}\right)$, inducing a larger sensitivity to high frequency surface meteorological variations. When forced by daily meteorological data, the model is able to represent fairly well a particular situation observed in 1995 when an exceptional secondary homogenization occurs because the spring surface temperature cools down close to the bottom temperature (Figure 4b).

[40] The model's difficulty in simulating some particular intra-annual phenomena (observed on individual water temperature profiles) may be due to the multiyear scaling of the meteorological parameters or to the use of daily measurements (which can smooth out extreme wind gusts for instance). In spite of that, the correlation coefficients between simulated and observed temperature for surface water and bottom water are always greater than 0.95 in both lakes considering not only daily forcing but also monthly forcing and climatologically forcing. Moreover, after the tuning, we also obtained good correlation coefficient between simulated and observed profiles for the three forcings which allowed us to appreciate the goodness of the fit.

[41] Nevertheless, the model, although developed for climatological purposes, is still able to represent some high frequency changes in the vertical temperature profiles due to daily or weekly changes in meteorological parameters. These extreme temporary modifications of the lake thermal structure do not appear in the annual mean and will be neglected in sensitivity studies of large steady state mean climatic fluctuations, for which the model is particularly suited.

\subsection{Ostracod Calcification Temperature $\left(T_{O}\right)$ : Observations and Simulations}

[42] Ostracods are small crustaceans protecting themselves within a calcitic carapace. During their life cycle they undergo eight moults, after each a new pair of valves, adopted to the new larger size, is produced. Each individual therefore can produce up to 9 pairs of valves, which, in their $\delta^{18} \mathrm{O}$, record a snapshot of ambient water temperature and water isotopic composition $\left(\delta^{18} O_{L}\right)$. A typical sample from which the isotopic record in Ammersee and Lac d'Annecy are produced, consists of a collection of up to 25 individual valves from the last five stages including adults of three species from the candona group. Population dynamics of these species have been derived from sediment surface samples in the hypolimnion of both lakes and indicate that these last five stages are passed preferentially in winter, starting with the onset of holomixis. Adults are mainly found during late winter and early spring, thus narrowing down the calcification period of those valves to roughly two months following the onset of turnover. In the following, the mean temperature for this period will be simply referred to as "ostracod temperature" $\left(T_{O}\right)$, although it is strictly the calcification temperature of the five last development stages of this special group and not of benthic deep-lake ostracods in general.

[43] Hypolimnetic lake temperature measurements are discontinuous; in general once or twice per month. As a result, the onset of homogenization cannot be precisely defined for each year. This leads to an uncertainty in the estimation of the modern ostracod temperature. For the modeling results we define the ostracod temperature for each year as a two-month average of the lake bottom temperature starting with the first homogenous profile. The error bars give the maximum and minimum observed temperatures during this time period. The climatological ostracod temperature (Figures 6a and 6c) is obtained by calculating the average of the yearly estimates (Figures $6 \mathrm{~b}$ and 6d).

[44] The ability of the model to simulate the lake hypolimnetic temperatures and of the timing of the homogenization period enforces its capacity of estimating the climatological ostracod temperature (as shown on Figures $6 \mathrm{a}$ and $6 \mathrm{c}$ ). Consequently, the model is accurate enough to perform sensitivity studies of the ostracod temperature under different climatic situations. The correct simulation of the lake hypolimnetic temperatures and of the timing of the homogenization period described in the previous sections warrant a correct simulation of the climatological ostracod temperature (Figures 6a and 6c) confirming that the model is able to perform sensitivity studies for this parameter used in paleoclimatic reconstructions.

[45] Interannual simulations performed with daily and monthly forcing enable us to evaluate the ability of the model to capture observed interannual fluctuations. For Lac d'Annecy, these simulations lead to realistic $T_{O}$ values and interannual trends (Figure 6b). For Ammersee, despite the uncertainties on the meteorological forcing discussed before and the difficulty of simulating correctly interannual fluctuations, the model captures some of the interannual changes and is correct for the climatological average (Figure 6d).

\subsection{Sensitivity Studies}

[46] In order to evaluate the bias on reconstructed $\delta^{18} O_{P}$ due to changes in ostracod calcification temperature, we have used the thermal lake model for the two sites to perform sensitivity studies on changes in three climatic 

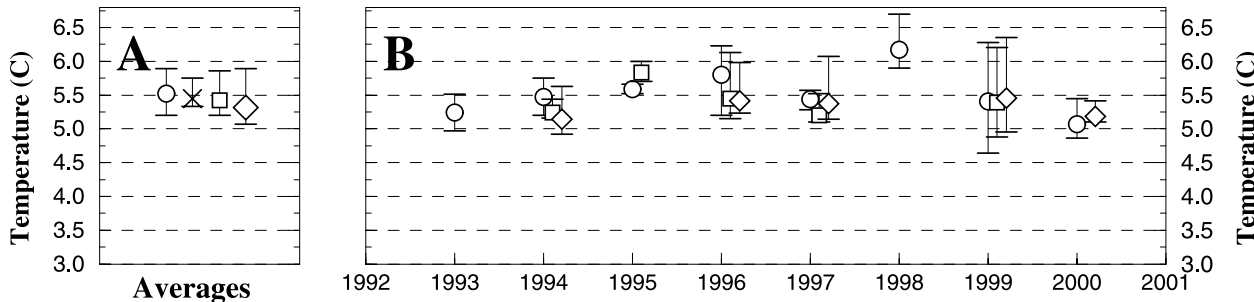

(2)

(2)

(2) (3)

(4)

(3)

(4) (4)
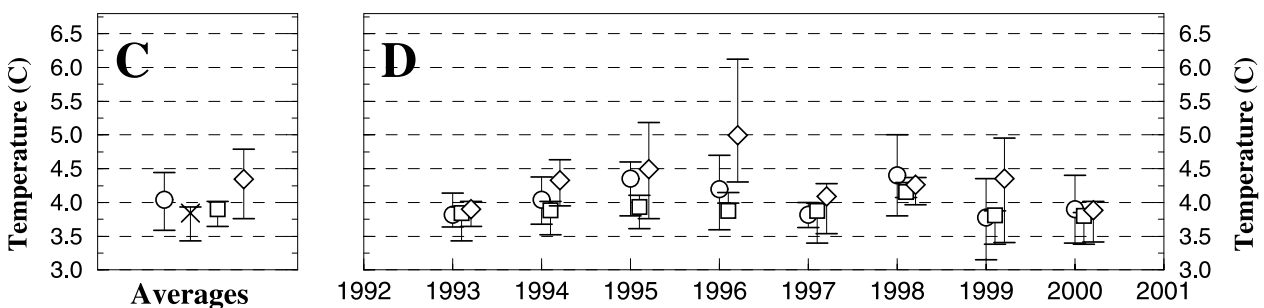

(5) (4)

(4)

(4)

(2)

(3)

(4) (4)

Figure 6. Observed (circles) and simulated (crosses, squares, and diamonds) ostracod temperature (mean temperature for the calcification period of candonidae at the maximum depth, $T_{O}$ ) in (a and b) Lac d'Annecy and in (c and d) Ammersee. Numbers in parenthesis indicate how many instantaneous observed profiles were used for the calculation of the observed $T_{O}$. Crosses illustrate results of steady state climatological simulations (Figures 6a and 6c). Circles (observational data), squares (monthly simulations) and diamonds (daily simulations) simulated $T_{O}$ illustrate decadal averages in Figures $6 \mathrm{a}$ and $6 \mathrm{c}$ and annual values in Figures $6 \mathrm{~b}$ and $6 \mathrm{~d}$. The error bars show the maximum and the minimum of the observed or simulated bottom water temperature used to calculate $T_{O}$.

parameters: the yearly air temperature (Ta), the air temperature seasonality and the yearly wind speed. For each lake, these studies have been done centered on the modern conditions (Table 4) and centered on the Younger Dryas conditions following Renssen et al. [2001] (Table 5). This allows us to bracket the probable extremes of the climatic development of the period recorded in the sediments of the two sites (roughly the last 15,000 years). We also plotted individually the climatic situations of the Last Glacial Maximum (LGM) [Masson et al., 1998], the mid-Holocene climatic optimum (MH) [Masson et al., 1999], and a prediction of the climate for the next century base on an IPCC prediction [Douville et al., 2002] (Figure 7). Here we considered the lake model runs on scenarios described by the climatological output field of atmospheric general circulation model runs (AGCM) for these periods, because we can thus use estimates of all the forcing parameters used by the lake model (Table 5). Even if neither of these AGCM runs can be considered to correctly represent the regional climate for these periods, we probably cover a sufficient range of climate to give an idea of the possible bias of ostracod calcification temperatures in the both lakes.

[47] We show the results for both lakes of two sets of 135 individual lake model runs (Figure 7). Within each of these sets we additionally vary the mean annual air temperature by \pm 1.5 and $\pm 3^{\circ} \mathrm{C}$, the temperature seasonality by $\pm 1, \pm 2$, \pm 3 , and $\pm 4^{\circ} \mathrm{C}$, and the mean wind speed by $\pm 10 \%$ with respect to the AGCM outputs. All other parameters (cloud cover, relative humidity, sea level-pressure) are kept constant either to their modern or YD levels. For this first-order study, we have ignored changes in the light extinction coefficient, lake level, the declination of the Earth and variations in the lake bathymetry. All sensitivity lake model result are obtained with steady state runs.
[48] The minimum simulated $T_{O}$ value is estimated to $3.7^{\circ} \mathrm{C}$ for the two sites; the thermal bias on ostracod based isotopic reconstructions will be measured by the deviation between the simulated $T_{O}$ and this minimum stable/step value. The existence of this minimum stable value, shown by Figure 7 , is due to the water density-temperature relationship. The sensitivity of density to small temperature variations is at a minimum around $4{ }^{\circ} \mathrm{C}$ and increases above and below this maximum density temperature. Consequently, during a cooling, the temperature averaged during the homogenized period of the water column can stay below $4^{\circ} \mathrm{C}$ before the formation of the inverse thermal stratification in a dimictic lake. After the onset of this stratification, the hypolimnetic water temperature remains constant to the last homogenized temperature before inversion and thus below $4^{\circ} \mathrm{C}$. Consequently, the minimum simulated $T_{O}$ (here $3.7^{\circ} \mathrm{C}$ ) is lower than the temperature of maximum density $\left(4^{\circ} \mathrm{C}\right)$ in a large range of climatic situations.

Table 5. AGCM Climatological Situations Results ${ }^{\mathrm{a}}$

\begin{tabular}{lccccc}
\hline & & \multicolumn{2}{c}{$\mathrm{YD}^{\mathrm{c}}$} & & \\
\cline { 3 - 5 } & LGM $^{\mathrm{b}}$ & Lac d'Annecy & Ammersee & $\mathrm{MH}^{\mathrm{d}}$ & $\mathrm{IPCC}^{\mathrm{e}}$ \\
\hline$\Delta T,{ }^{\circ} \mathrm{C}$ & -5.3 & -2.4 & -4.8 & 0.6 & 2.5 \\
$\Delta a m p l \bar{T},{ }^{\circ} \mathrm{C}$ & 6.0 & 3.9 & 5.6 & 3.2 & 0.8 \\
$\Delta w, \mathrm{~m} \mathrm{~s}^{-1}$ & 1.1 & 1.36 & 1.32 & 1.1 & 1.0 \\
$\Delta C C$ & 1.0 & 1.0 & 1.0 & 1.0 & 1.0 \\
$\Delta R H, \%$ & 0.9 & - & - & 1.0 & 1.0 \\
\hline
\end{tabular}

${ }^{a}$ Values of the correction parameters relative to the recent climatic situations in Table 4.

${ }^{\mathrm{b}}$ From Masson et al. [1998].

${ }^{\mathrm{c}}$ From Renssen et al. [2001].

${ }^{\mathrm{d}}$ From Masson et al. [1999].

${ }^{\mathrm{e}}$ From Douville et al. [2002]. 

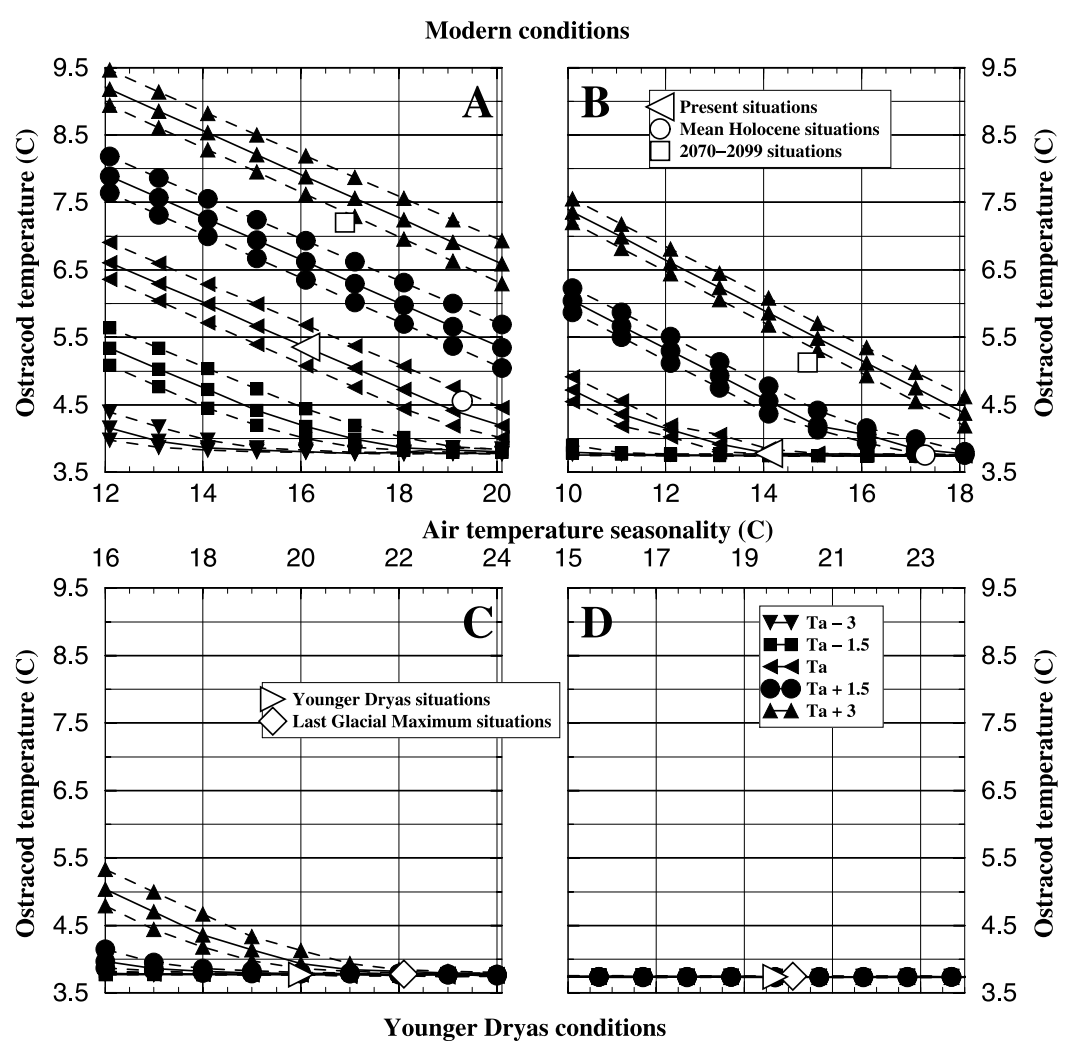

Figure 7. Sensitivity studies of the ostracod temperature for variations of the yearly air temperature (Ta), of the air temperature seasonality and of the yearly wind speed centered on the modern conditions ((a) Lac d'Annecy; (b) Ammersee) and centered on the Younger Dryas conditions ((c) Lac d'Annecy; (d) Ammersee). We considered Ta varying by \pm 1.5 and $\pm 3^{\circ} \mathrm{C}$ (filled symbols), the air temperature seasonality varying by $\pm 1, \pm 2, \pm 3$, and $\pm 4^{\circ} \mathrm{C}$ (horizontal axis) and the yearly wind speed varying by $\pm 10 \%$ (upper dashed lines: $-10 \%$ and lower dashed lines: $+10 \%$ ), in order to bracket the probable extremes of the climatic development of the period recorded in the sediments of the two lakes. Opaque symbols point on the present situations (triangles left), the mid-Holocene climatic optimum situations (circles), a prediction of the climate for the end of the next century (squares), the Younger Dryas situations (triangles right) and the Last Glacial Maximum situations (diamonds). Climatic situations outputs result of PMIP (Paleoclimate Modeling Inter-comparison Project) boundary conditions [Masson et al., 1999] for mid-Holocene (6000 BP) time periods, of ECHAM4/T42-REMO runs [Renssen et al., 2001] for the Younger Dryas in Europe, of LMCELMD5 runs [Masson et al., 1998] for the Last Glacial Maximum (21,000 years BP) and of the coupled atmosphere-ocean Climate Model of the Centre National de Recherches Météorologiques using the SRES-B2 IPCC scenario [Douville et al., 2002] for the end of the next century.

[49] Despite currently different lakes' characteristics between the two lakes, their simulated $T_{O}$ show similar trends when the same forcing is applied, because the same physical thermal mechanisms are simulated (Figures $7 \mathrm{a}$ and $7 \mathrm{~b}$ ). The modern climate near Lac d'Annecy, the local light extinction coefficient and the topography lead to a modern monomictic situation and an ostracod temperature higher than $3.7^{\circ} \mathrm{C}$ (Figure 7a); in contrast, Ammersee is purely dimictic and the ostracod temperature nowadays is the minimum value (Figure 7b).

[50] Steady state simulations around colder climatic conditions give similar minimal ostracod temperatures for the two lakes which are then both dimictic (Figures 7c and 7d). Starting from these conditions, reasonable changes in mean air temperature (typically $\pm 3^{\circ} \mathrm{C}$ ), seasonal amplitude (typically $\pm 20 \%)$ and wind speed $( \pm 10 \%)$ have no impact on the ostracod temperature. In this case, no thermal-induced bias is simulated and the fluctuations in calcite isotopic composition should reflect directly the fluctuations in deep lake water isotopic composition during the calcification period, which, due to the preceding and/or continuing holomixis, is also an excellent mean for the entire water column.

[51] Steady state simulations around the modern climatic conditions lead to a more complex picture (Figures 7a and 7b). For Lac d'Annecy, we show that the ostracod temperature increases (1) when the annual mean surface air temperature increases, (2) when the seasonal amplitude of the surface air temperature decreases, and (3) when the mean wind speed decreases. The ostracod temperature decrease is limited by the change in lake thermal behavior: when the lake becomes dimictic, the ostracod temperature reaches the minimum value. Ammersee is already a dimictic lake; starting from modern conditions, the ostracod temperature will not be sensitive to a decrease of the surface air 
temperature, to an increase of the seasonal air temperature amplitude, or to an increase of the wind speed. Note that the sensitivity to wind speed changes is larger for Annecy than for Ammersee because Lac d'Annecy is shallower than Ammersee.

[52] We have therefore shown that small climatic fluctuations in warmer climatic conditions may induce a thermal bias in the isotopic signal recorded in benthic ostracod calcite, due to changes in deep lake water temperature. We can quantify roughly the error on paleoclimatic reconstructions for which changes in lake temperature are ignored. Let us consider a small warming such as the socalled medieval optimum. If only the mean surface air temperature is modified by $1^{\circ} \mathrm{C}$, the isotopic composition of the precipitation should increase by about $0.6 \%$ due to the modern spatial isotope-temperature gradient (typically $0.6 \% /{ }^{\circ} \mathrm{C}$ ) [Rozanski et al., 1992; von Grafenstein et al., 1996]. Assuming no change in the hydrology of the catchment and the lake, the change in the lake water isotopic composition should be about the same $(+0.6 \%$ o). Our thermal lake model simulates a warming of the deep lake temperature by about $0.84^{\circ} \mathrm{C}$ for Lac d'Annecy, inducing a thermal bias on the calcite isotopic composition of $-0.21 \%$ or $-0.19 \%$, deduced from Friedman and $O$ 'Neil [1977] or Kim and O'Neil [1997], respectively. The actual calcite isotopic composition should vary by $0.60-0.21=$ $+0.39 \%$. Without considering the thermal bias, a paleoclimatic reconstruction from this calcite would lead us to interpret this amplitude as purely driven by lake water isotopic composition and suggest a past temperature change of $0.39 / 0.6=0.65^{\circ} \mathrm{C}$ instead of the $1^{\circ} \mathrm{C}$ considered here. This simplified calculation ignoring compensation effects between various climate parameters and changes in lake and catchment hydrology suggests that deep lake thermal effects could lead to an underestimation of past higher-than-today temperature changes by roughly $35 \%$. Ammersee ostracod temperature being less sensitive to surface temperature changes, the underestimation would be smaller $(\sim 17 \%)$.

[53] For the mid-Holocene (slightly warmer in mean annual air temperature), the GCM results enable us to also estimate the changes in wind speed and temperature seasonal amplitude. In this case, the ostracod temperature is slightly colder than nowadays at Lac d'Annecy $\left(-0.8^{\circ} \mathrm{C}\right)$ mainly due to the increase in seasonal temperature amplitude (in response to insulation). In this particular case, ignoring the thermal bias will lead to an overestimation of the past temperature change. However, for Ammersee, the ostracod temperature is not modified and no thermal bias should be observed.

\section{Conclusion and Perspectives}

[54] Here we have used a classical one-dimensional eddy diffusion lake thermal model including lake ice and refined it by including a seasonal light extinction coefficient model, in order to simulate changes in lake vertical temperature profile and specifically lake bottom temperature. We have also adapted the available meteorological observations to construct the most realistic meteorological forcing of the lake considering micrometeorological variations. We have tested our model for two different European lakes (Lac d'Annecy in France and Ammersee in Germany) chosen for benthic ostracod-based paleoclimatic reconstructions. The comparison between simulations and observations available for these two lakes (surface and deep lake temperature, thermocline depth, onset and duration of the mixing period) gives confidence in the ability of this model to capture the physical mechanisms responsible for the mean surface and deep lake temperature values, but also for their seasonal and interannual variabilities.

[55] Paleoclimatic reconstructions based on benthic ostracod calcite isotopic composition classically assume that the deep lake temperatures are constant. We performed climatic sensitivity studies with our thermal model for the two lakes and show that while the calcification temperature is constant during glacial conditions, it may vary significantly during interglacial conditions.

[56] In this paper, we have discussed only steady state simulations. In future studies, we plan to evaluate the transient lake response to recent long-term meteorological fluctuations available through homogenized data sets and historical records (e.g., the presence of lake ice). As century-long meteorological data sets are not available for all necessary forcing parameters, we need to evaluate which change and what frequency of changes control the intraannual and interannual water temperature fluctuations. Ideally, paleoenvironmental studies in addition to stable isotope records can provide qualitative or quantitative information, which will at least allow us to give some limited estimates of climatic parameters. For example, continuous ostracod countings available from deep lake sediments at Ammersee indicate that ventilation has occurred each year from 15,000 to 5000 years BP. We can use this information to run various transient deglaciation simulations with various climate change rates to quantify the maximum possible rates compatible with ostracod survival. Other possible proxies could include pollen and/or chironomid based temperature and precipitation estimates, or water temperature estimates based on the comparison of shallow water and deep-lake ostracod oxygen isotope records [von Grafenstein, 2002].

[57] Transient lake simulations will also be performed for future climatic changes predicted by climate models. Indeed, future warming may inhibit winter mixing and have large impacts on biological activity in the lake and therefore impact the local economy (e.g., fishing and tourism).

[58] This model will be improved by the incorporation of the water stable isotopes in the lake and catchment, which will enable us to quantify the isotopic connection between the atmospheric precipitation and the deep lake. The thermal model itself could be extended to other lakes provided that seasonal variations of light extinction coefficient can be estimated. Past changes in this parameter may have also had a significant impact of the lake heat budget as suggested from the comparison between observed and simulated winter mixing periods. Empirical relationships between algal productivity, catchment erosion and local climatic conditions could help to develop a parameterization for past and future changes of the light extinction coefficient and take this effect into account for sensitivity studies.

[59] Acknowledgments. This work has been funded by ANDRA, CEA, and CNRS. We thank V. Guichard of SILA and B. Lenhardt of Wasserwirtschaftsamt Weilheim, Oberbayern, for providing lake temperature measurements from Lac d'Annecy and from Ammersee, respectively. We thank S. Planton for providing results of the model of CNRM using the 
SRES-B2 IPCC scenario and $\mathrm{H}$. Renssen for making available results of ECHAM4/T42-REMO runs for the Younger Dryas in Europe. Data of the bathymetry (Université de Savoie-IFREMER) of Lac d'Annecy was compiled by M. Desmet (LGCA). We also appreciate three anonymous reviewers for their constructive criticisms and valuable comments. This is contribution LSCE-967.

\section{References}

Benedetti-Crouzet, E., Etude géodynamique du lac d'Annecy et de son bassin versant, Ph.D. thesis, Univ. é de Paris VI, Paris, 1972.

Benson, L., and F. Paillet, HIBAL: A hydrologic-isotopic-balance model for application to paleolake systems, Quat. Sci. Rev., 21, 1521-1539, 2002

Carmack, E. C., and D. M. Farmer, Cooling processes in deep, temperate lakes: A review with examples from two lakes in British Columbia, J. Mar. Res., 40(suppl.), 85-111, 1982

Dansgaard, W., Stable isotopes in precipitation, Tellus, 16, 436-468, 1964

Douville, H., F. Chauvin, S. Planton, J.-F. Royerand, D. Salas-Mélia, and S. Tyteca, Sensitivity of the hydrological cycle to increasing amounts of greenhouse gases and aerosols, Clim. Dyn., 20, 45-68, 2002.

Farmer, D. M., and E. Carmack, Wind mixing and restratification in a lake near the temperature of maximum density, J. Phys. Oceanogr., 11, 15161533,1982

Friedman, I., and J. R. O’Neil, Compilation of stable isotope fractionation factors of geochemical interest, in Data of Geochemistry, edited by I. Friedman and J. R. O'Neil, pp. KK1-KK12, U.S. Geol. Surv., Washington, D. C., 1977.

Gat, J., and G. Lister, The catchment effect on the isotopic composition of lake waters; its importance in palaeolimnological interpretations, Paläoklimaforschung, 15, 1-15, 1995

Gonfiantini, R., Environmental isotopes in lakes studies, in Handbook of Environmental Isotope Geochemistry, edited by P. Frits and J.-C. Fontes, pp. 113-168, Elsevier Sci., New York, 1986.

Heggen, R. J., Thermal dependent properties of water, J. Hydrol. Eng., 109, 298-302, 1983

Henderson-Sellers, B., A new formula for latent heat of vaporization of water as a function of temperature, Quat. J. Res. Meteorol. Soc., 110, $1186-1190,1984$.

Henderson-Sellers, B., New formulation of eddy diffusion thermocline models, Appl. Math. Model., 9, 441-446, 1985.

Henderson-Sellers, B., Calculating the surface energy balance for lake and reservoir modeling: A review, Rev. Geophys., 24, 625-649, 1986.

Hostetler, S., Simulation of lake ice and its effect on the late-Pleistocene evaporation rate of Lake Lahontan, Clim. Dyn., 6, 43-48, 1991.

Hostetler, S. W., and P. Bartlein, Simulation of lake evaporation with application to modeling lake level variations of Harney-Malheur lake, Oregon, Water Resour. Res., 26, 2603-2612, 1990.

Hostetler, S., and L. Benson, Paleoclimatic implications of the high stand of Lake Lahontan derived from models of evaporation and lake level, Clim. Dyn., 4, 207-217, 1990.

Hostetler, S. W., and L. Benson, Stable isotopes of oxygen and hydrogen in the Truckee River-Pyramid Lake surface-water system. 2. A predictive model of $\delta^{18} \mathrm{O}$ and $\delta^{2} \mathrm{H}$ in Pyramid Lake, Limnol. Oceanogr., 39, 356364, 1994.

Hostetler, S., and F. Giorgi, Effects of $2 \times \mathrm{CO}_{2}$ climate on two large lake systems: Pyramid Lake, Nevada, and Yellowstone Lake, Wyoming, Global Planet. Change, 10, 43-54, 1995.

Johnsen, $\mathrm{S}$., et al., Irregular glacial interstadials recorded in a new Greenland ice core, Nature, 359, 311-313, 1992.

Jouzel, J., et al., Validity of the temperature reconstruction from water isotopes in ice cores, J. Geophys. Res., 102, 26,471-26,487, 1997.

Kim, S.-T., and J. O'Neil, Equilibrium and non-equilibrium oxygen isotope effects in synthetic carbonates, Geochim. Cosmochim. Acta, 61, 34613475,1997

Liston, G. E., and D. K. Hall, An energy-balance model of lake-ice evolution, J. Glaciol., 41, 373-382, 1995 .
Masson, V., S. Joussaume, S. Pinot, and G. Ramstein, Impact of parametrizations on simulated winter mid-Holocene and Last Glacial Maximum changes in the Northern Hemisphere, J. Geophys. Res., 103, 8935-8946, 1998.

Masson, V., R. Cheddadi, P. Braconnot, S. Joussaume, and D. Texier, midHolocene climate in Europe: What can we infer from PMIP model-data comparisons?, Clim. Dyn., 15, 163-182, 1999.

Orlob, G. T., and L. G. Selna, Temperature variations in deep reservoirs, J. Hydraul. Div. Soc. Civ. Eng., 96, 391-410, 1970.

Patterson, J. C., and P. F. Hamblin, Thermal simulation of a lake with winter ice cover, Limnol. Oceanogr., 33, 233-338, 1988.

Peeters, F., D. M. Livingstone, G.-H. Goudsmit, R. Kipfer, and R. Forster, Modeling 50 years of historical temperature profiles in a large central European lake, Limnol. Oceanogr., 47, 186-197, 2002

Pourriot, R., and M. Meybeck (Eds.), Limnologie Physique et Chimique, Masson, Paris, 1995.

Renssen, H., R. Isarin, D. Jacob, R. Podzun, and J. Vandenberghe, Simulation of the Younger Dryas climate in Europe using a regional climate model nested in a AGCM: Preliminary results, Global Planet. Change, $30,41-57,2001$

Rozanski, K., L. Araguás-Araguás, and R. Gonfantini, Relation between long-term trends of oxygen-18 isotope composition of precipitation and climate, Science, 258, 981-985, 1992.

Rozanski, K., L. Araguás-Araguás, and R. Gonfantini, Isotopic patterns in modern global precipitation, in Climate Change in Continental Isotopic Records, Geophys. Monogr. Ser, vol. 78, edited by P. Swart et al., pp. $1-$ 36, AGU, Washington, D. C., 1993.

van Duin, E. H. S., G. Blom, F. J. Los, R. Maffione, R. Zimmerman, C. F. Cerco, M. Dortch, and E. P. H. Best, Modeling underwater light climate in relation to sedimentation resuspension, water quality and autotrophic growth, Hydrobiologia , 444, 25-42, 2001.

Vassiljev, J., The simulated response of lakes to changes in annual and seasonal precipitation: Implication for Holocene lake-level changes in northern Europe, Clime Dyn, 14, 791-801, 1998.

Vassiljev, J., and S. Harrison, Simulating the Holocene lake-level record of Lake Bysjon, southern Sweden, Ouat. Res., 49, 62-71, 1998.

Vassiljev, J., S. Harrison, S. Hostetler, and P. J. Bartlein, Simulation of longterm thermal characteristics of three Estonian lakes, J. Hydrol., 163, $107-123,1994$

Vassiljev, J., S. Harrison, and A. Haxeltine, Recent lake-level and outflow variations at Lake Viljandi, Estonia: Validation of a coupled lake-catchment modeling scheme for climate change studies, J. Hydrol., 170, $63-$ $77,1995$.

von Grafenstein, U., Oxygen-isotope studies of ostracods from deep lakes, in The Ostracoda: Applications in Ouaternary Research, Geophys. Monogr. Ser., vol. 131, edited by A. R. Chivas and J. A. Holmes, pp. 249-265, AGU, Washington, D. C., 2002.

von Grafenstein, U., H. Erleinkeuser, J. Müller, P. Trimborn, and J. Alefs, A 200 years mid-European air temperature record preserved in lake sediments: An extension of the $\delta^{18} O_{p}$-air temperature relation into the past, Geochim. Cosmochim. Acta, 60, 4025-4036, 1996.

von Grafenstein, U., H. Erleinkeuser, A. Brauer, J. Jouzel, and S. J. Johnsen, A mid-European decadal isotope-climate record from 15,500 to 5000 years B. P., Science, 284, 1654-1657, 1999a.

von Grafenstein, U., H. Erleinkeuser, and P. Trimborn, Oxygen and carbon isotopes in modern fresh-water ostracod valves: Assessing vital offsets and autecological effects of interest for palaeoclimate studies, Palaeogeogr. Palaeoclimatol. Palaeoecol., 148, 133-152, 1999b.

P.-A. Danis, V. Masson-Delmotte, and U. von Grafenstein, Laboratoire des Sciences du Climat et de l'Environnement, (UMR CEA/CNRS 1572, CEA) Saclay, Bat 709, F-91191 Gif-sur-Yvette Cedex, France. (danis@1sce.saclay.cea.fr; masson@1sce.saclay.cea.fr; uligraf@1sce.saclay. cea.fr) 